\title{
QUALITY ASSESSMENT OF THE ESSENTIAL OILS FROM ARTEMISIA GMELINII AND ORIGANUM MAJORANA OF NEPALI ORIGIN
}

\author{
Suraj Shrestha*, Daya Ram Nyaupane*, Shoji Yahara**, Meena Rajbhandari*** and Mohan B. Gewali* \\ *Central Department of Chemistry, Tribhuvan University, Kirtipur, Kathmandu, Nepal. \\ **Faculty of Pharmaceutical Sciences, Kumamoto University, Japan. \\ ***Research Center for Applied Science and Technology, Tribhuvan University, Kirtipur, Kathmandu, Nepal.
}

\begin{abstract}
The chemical composition and physicochemical parameters of the essential oil obtained from Artemisia gmelinii Web. et Stechm and Origanum majorana L. were determined. GC-MS technique was used for the analysis of the chemical composition of the oils. The chemical components were identified on the basis of retention time and comparing with mass spectral database of standard compounds. Relative amounts of detected compounds were calculated on the basis of GC peak areas. More than 35 components were detected in A. gmelinii oil and 12 of them were identified. The main constituents were 2-methyl-1-methylene-3-(1-methylethenyl)-cyclopentane, 1,8-cineole, 1-(1,5-dimethyl-4-hexenyl)-4-methyl-benzene, camphor and S-(+)-5-(1-hydroxy-1-methylethyl)-2-methyl-2cyclohexen-1-one. More than 30 constituents were detected in $O$. majorana oil and 11 of them were identified. The major constituents were monoterpenes and to a small extent of sesquiterpenes such as $Z$-sabinene hydrate, $E$-sabinene hydrate, terpinen-4-ol, linalool, $y$-terpinen, $p$-cymene, $\alpha$-phellandrene and $\alpha$-terpineol. The physical properties such as specific gravity, refractive index and optical rotation and the chemical properties such as saponification value, acid number and iodine number of the two oils were examined.
\end{abstract}

Keywords: Essential oils; Artemesia gmelinii; Oreganum majorana; GC-MS; Physiochemical parameter.

\section{INTRODUCTION}

Artemisis gmelinii (Asteraceae) is a perennial herb distributed in the Himalayan region of Manang and Mustang district. It is commonly known as Russian Wormwood and locally called Bajha. It has extensive use in rural area of Mustang and other districts for the treatment of various diseases such as nose swelling, ear pain, allergies, skin wounds and also used as incense and fodder for livestock ${ }^{1}$. Leaves and flowers extracts are used as medicine for headache, cold, cough, abdominal upsets and hepatitis ${ }^{2}$. Some work related to the chemical constituents and fungitoxicity of $A$. gmelinii are reported $3-9$.

Oreganum majorana (Labiatae) is distributed in the central Nepal at altitude of about $1,300 \mathrm{~m}$ in moist places. It is commonly known as sweet marjoram and locally known as Maruwa phul or 'mu swan'. It is reported to have antispasmodic, digestive, expectorant and diuretic properties and effective for cure of asthma, cough and widely used in gastronomy and natural medicine. The volatile oil has good potentials in cosmetic, pharmaceutical, perfumery, food and flavor industries ${ }^{10}$, 11 . It is offered to Gods and Goddesses. Considerable work on the composition of essential oils of O. majorana and its ovicidal and antibacterial activities are reported ${ }^{12-18}$.

Despite the reputation earned by medicinal and aromatic plants of Nepal, the chemical constituents of the essential oil of A. gmelinii and O. majorana of Nepalese origin has not previously been investigated. Thus, the present study has been conducted for the determination of chemical constituents of the essential oil by GC-MS technique and the determination of different physicochemical properties of the oil. This will help to access the quality of the oil which is important in the production of high value essential oils that will help to improve the economic condition of the community as well as the nation. 


\section{MATERIALS AND METHODS}

\section{Plant materials}

The aerial parts of $A$. gmelinii were collected from Jhong area of Mustang district at an altitude of $3700 \mathrm{~m}$. The aerial parts of $O$. majorana was collected from flower vender at Ason market in Kathmandu valley. The plants were authenticated by Prof. R. P. Chaudhary, Central Department of Botany, Tribhuvan University. Voucher specimens were deposited at Research Center for Applied Science and Technology, RECAST, Tribhuvan University.

\section{Volatile oil extraction}

The dried and powdered plant materials (100 g each) were hydrodistiled for 4-5 h in a Clevenger type apparatus to yield two oils. The oils were collected and dried over $\mathrm{Na}_{2} \mathrm{SO}_{4}$ and stored at $4{ }^{\circ} \mathrm{C}$ for further use.

\section{Gas chromatography-mass spectrometry}

Analytical GC was recorded on gas chromatograph with a flame ionization detector using a capillary $30 \mathrm{~m}$ DB-5 column (J and W Scientific, USA) with $0.25 \mathrm{~mm}$ i.d. and $0.1 \mathrm{~mm}$ film thickness. The temperature program was $50^{\circ} \mathrm{C}$ for 2 minute and gradually increased to $300^{\circ} \mathrm{C}$ at $10^{\circ} \mathrm{C} /$ minute and kept for 3 minutes. The carrier gas was Helium at a flow rate $1 \mathrm{~mL} / \mathrm{min}$. MS was operated in the electron impact mode with an ionization energy of $70 \mathrm{eV}$ on a JEOL AX505 mass spectrometer connected to HP-9000 computer system.

The detected compounds were identified by processing the raw GC-MS data and comparing with National Institute of Standard and Technology, NIST, USA mass spectral database and from retention times and mass spectra of standard compounds. Relative amounts of detected compounds were calculated based on GC peak areas.

\section{Determination of physical parameters}

Physical parameters were determined according to the method of Guenther ${ }^{19}$.

\section{Specific gravity determination}

An ignition tube of known weight (W) was filled first with essential oil and then with water and the respective weight $\mathrm{W}_{1}$ and $\mathrm{W}_{2}$ was determined. Then, the specific gravity was calculated using the formula,

$\mathrm{dt}=\underline{\mathrm{W} 1-\mathrm{W}}$

\section{Refractive index determination}

The refractive index of the oil was measured by using Abbe's refractometer.

\section{Optical Rotation Determination}

Different concentration of oil solutions $(1.0 \%, 0.5 \%$, $0.25 \%$ ) were prepared in methanol and the optical rotation was measured for the solutions of different concentrations. Then the specific rotation was calculated using the formula,

$[\alpha]_{\mathrm{D}}^{\mathrm{t}}=\frac{\mathrm{a}}{l \times c}$

Where, $\alpha$ is the angle of rotation of the plane of plane polarized light, 1 is the length of polarimeter tube $(\mathrm{mm})$ and $\mathrm{c}$ is the concentration of oil solution.

\section{Determination of chemical parameters}

\section{Saponification value determination}

Saponification value was determined by standard procedure. Jatamansi oil ( $0.5 \mathrm{~g})$ was accurately weighed and dissolved in $10 \mathrm{~mL}$ of ethanol and then $10 \mathrm{~mL}$ of $2.5 \mathrm{~N}$ potassium hydroxide $(\mathrm{KOH})$ solution was added. This procedure was performed in duplicate and blank experiment was also performed omitting the oil. The flask was refluxed for two hours then cooled. The unreacted $\mathrm{KOH}$ was titrated with standard $\mathrm{N} / 2$ oxalic acid by adding 2-3 drops of phenolphthalein indicator. Then, the saponification value was determined using the following equation.

Saponification value $($ S.V. $)=(56 \times($ V1-V2 $) \times 1000) /$

$$
(2 \times 1000 \times \mathrm{W})
$$

Where, $\mathrm{W}$ is the weight of oil, $\mathrm{V}_{1}$ is the volume of $\mathrm{N} / 2$ oxalic acid for blank, $\mathrm{V}_{2}$ is the volume of $\mathrm{N} / 2$ oxalic acid for sample.

\section{Acid value determination}

Acid value was determined according to the method of Guenther ${ }^{19}$. Oil (0.5 gm) was accurately weighted and dissolved in $10 \mathrm{~mL}$ of $95 \%$ ethanol and 2-3 drops of phenolphthalein indicator was added. The free acid was then titrated with standard $0.1 \mathrm{~N}$ aqueous sodiumhydroxid solution by adding the alkali dropwise at a uniform rate of about 30 drops per minute. The content of the flask was continuously agitated. The first appearance of the red coloration that did not fade within 10 seconds was considered the end point. Then, the acid value (A.V) was calculated using the following equation,

Acid value $=5.61($ number of $\mathrm{ml}$ of $0.1 \mathrm{~N} \mathrm{NaOH})$

Weight of Sample in gram

\section{Iodine number determination}


Iodine number was determined according to the method of Guenther ${ }^{19}$. Oil $(0.25 \mathrm{gm})$ was dissolved in $10 \mathrm{ml}$ of chloroform. Then $25 \mathrm{ml}$ of iodobromide solution was added and allowed to stand for 30 minutes in dark. Again $30 \mathrm{ml}$ of $1 \mathrm{~N}$ potassium iodide and 100 $\mathrm{ml}$ of distilled water were added and the liberated iodine was titrated with $\mathrm{N} / 10$ solution of sodium thiosulphate with constant shaking. When iodine color became quite pale, $1 \mathrm{ml}$ of $1 \%$ starch solution was added and the titration was continued until the blue color was discharged. A blank test was also carried out parallel under identical condition. The iodine number was determined using the formula,

Iodine number (I.N.) $=1.269(\mathrm{~V} 1-\mathrm{V} 2)$

\section{W}

Where, $\mathrm{W}$ is the weight of sample, $\mathrm{V}_{1}$ is the number of $\mathrm{ml}$ of thiosulphate consumed by the blank, $\mathrm{V}_{2}$ is the number of $\mathrm{mL}$ of thiosulphate consumed by the test sample.

Iodobromide solution was prepared by dissolving iodine (13.2 gm ) in $1000 \mathrm{~mL}$ glacial acetic acid by gentle heating. The solution was cooled to $25^{\circ} \mathrm{C}$ and the iodine content in $20 \mathrm{ml}$ was determined by titration with N/10 Sodium thiosulphate. To the remainder of the solution a quantity of bromine molecularly equivalent to that of the iodine present was added.

\section{RESULT AND DISCUSSION}

The essential oil obtained by hydrodistillation of the aerial parts of $A$. gmelinii was orange coloured slightly viscous liquid with characteristic odor and $O$. majorana was pale yellow slightly viscous with strong sweet and spicy odor. The yields were $0.4 \%$ for $A$. gmelinii and $1.1 \%$ for $O$. majorana on dry weight basis.

The GC analysis of the essential oils of $A$. gmelinii allowed the detection of 35 components and 12 of them were identified on the basis of retention time and comparing with mass spectral database of standard compounds. They accounted for $72.84 \%$ of the essential oil. The major constituents were 2-methyl-1-methylene3-(1-methylethenyl)-cyclopentane, eucalyptol, 1 -(1,5-dimethyl-4-hexenyl)-4-methylbenzene, camphor, and s-(+)-5-(1-hydroxy-1-methylethyl)2-methyl-2-cyclohexen-1-one. In the case of $O$. majorana, 30 components were detected of which 11 were identified on the basis of retention time and comparing with mass spectral database of standard compounds. They accounted for $89.09 \%$ of the essential oil. Majority of components were monoterpenoids . The major constituents were terpinen-4-ol, linalool, $y$-terpinen, $\alpha$-terpineol $\alpha$-phellandrene, and $p$ - cymene. The identified compounds, their retention times and percentages are listed in Table 1.
It was reported that in $A$. gmelinii of central Asian origin ${ }^{5}$ the main components were 1,8-cineol (21-40\%), camphor (10-31\%), borneol (4-17\%) and terpineol-4 (4-8\%). In Chinese origin ${ }^{7}$, cineole $(43.98 \%)$, camphor $(11.56 \%)$ and borneol $(16.82 \%)$ were the main constituents. In Himalayan origin ${ }^{8}$, the main constituents were artemisia ketone $(28.2 \%)$ and 1,8-cineol (13.0\%). In our study 1,8-cineol $(14.50 \%)$ and camphor $(10.95 \%)$ were the major constituents. The presence of an additional major component, 1-(1,5-dimethyl-4-hexenyl)-4-methylbenzene (13.22\%) and a 2,5-bis(1,1-dimethylethyl)thiophene $(2.27 \%)$ which was not previously reported in A. gmelinii of Kazakasthan ${ }^{6}$ indicated that A. gmelinii of Nepalese origin is different from that collected from other geographical regions of the world.

Carvacrol (78.27-79.46\%) was the major component of $O$. majorana collected from Turkey ${ }^{12}$. Terpinen-4-ol $(38.40 \%)$ and cis-sabinene hydrate $(15.0 \%)$ were the major constituents collected from Reunion Island ${ }^{13}$. Linalyl acetate $(26.1 \%)$ and sabinene $(12.0 \%)$ were the major components of the oil collected from Iran ${ }^{14}$. In other studies, the main constituents from Venezuala ${ }^{15}$ were cis-sabinene hydrate $(30.2 \%)$, terpinen-4-ol $(28.8 \%), \gamma$-terpinene $(7.2 \%)$ and India ${ }^{16}$ were terpinen4-ol (31.15\%), cis-sabinene hydrate (15.76\%), $p$-cymene $(6.83 \%)$. In our study terpinen-4-ol $(22.42 \%)$, $\gamma$-terpinene (14.69\%), linalool (11.61\%) were the major constituents. Our majorana oil composition was found to be close to that reported in the literature except for some minor variations. The high content of terpinen-4ol is due to the rearrangements of components during distillation process and cis-sabinene hydrate which is responsible for the intense spicy "marjoram" aroma is absent in our sample ${ }^{16}$.

The physicochemical properties of the oils were evaluated using the standard procedure and the results are presented in Table 2. The specific gravity and refractive index values are close to each other. Both oils are dextrorotatory with the greater angle of rotation for A. gmelinii oil. The saponification value of essential oil of $A$. gmelinii is slightly higher than that of O. majorana it indicates that the former contains higher molecular weight fatty acid. The acid value of $O$. majorana was found to be lower than $A$. gmelinii. The iodine value of essential oil of $O$.

majorana is greater than that of $A$. gmelinii thus reflecting a high degree of unsaturation in essential of O. majorana.

In conclusion, based on the chemical profile and physicochemical parameters the quality of two essential oils obtained from $A$. gmelinii and $O$. majorana are close to the oil produced in other parts of the world. The minor differences in the composition of the oil may arise due to the difference in chemotypes, environmental factors and condition of growth ${ }^{20}$. 
Table 1: Main constituents of two essential oils

\begin{tabular}{|c|c|c|c|c|}
\hline No & Constituents of A. gmelinii & $\mathrm{GC} \%$ & Constituents of $O$. majorana & $\mathrm{GC} \%$ \\
\hline 1 & Eucalyptol & 14.50 & Caryophyllene & 2.16 \\
\hline 2 & Camphor & 10.95 & $\alpha$-phallandrene & 9.18 \\
\hline 3 & 2-Methyl-1-methylene-3-(1-methylethenyl)-cyclopentane & 3.51 & $\alpha$-terpineol & 7.02 \\
\hline 4 & s-(+)-5-(1-hydroxy-1-methylethyl)-2-methyl-2 - cyclohexen-1-one & 7.64 & Terpinen-4-ol & 22.42 \\
\hline 5 & A,4-Dimethyl-3-cyclohexene-1-acetaldehyde & 4.34 & Sabinene & 1.89 \\
\hline 6 & (s)-1-Methyl-4-(5-methyl-1-methylene-4-hexenyl)-cyclohexene & 1.03 & $\alpha$-pinene & 1.48 \\
\hline 7 & 1-(1,5-dimethyl-4-hexenyl)-4-methyl-benzene & 13.22 & Linalool & 11.61 \\
\hline 8 & 5-(1,5-Dimethyl-4-hexenyl)-2-methyl-1,3-cyclohexadiene & 3.72 & Terpinolene & 3.52 \\
\hline 9 & 2-Ethyl-3-methoxy-2-cyclopentenone & 3.93 & $\gamma$-terpinene & 14.69 \\
\hline 10 & Flameno & 15.17 & p-cymene & 8.91 \\
\hline 11 & (-)-Spathuleno & 13.10 & $\alpha$-terpinene & 6.21 \\
\hline \multirow[t]{2}{*}{12} & 2,5-bis(1,1-dimethylethyl) thiophene & 2.27 & - & - \\
\hline & Total & 72.84 & & 89.09 \\
\hline
\end{tabular}

Table 2:

\begin{tabular}{lcc}
\hline Parameters & A. gmelinii & O. majorana \\
\hline Specific gravity & 0.938 & 0.895 \\
Refractive index & 1.492 & 1.472 \\
Specific rotation & $+45.5^{\circ}$ & $15.0^{\circ}$ \\
Saponification value & 225.87 & 193.30 \\
Acid value & 47.39 & 3.22 \\
Iodine value & 51.91 & 201.70 \\
\hline
\end{tabular}

\section{ACKNOWLEDGEMENT}

Volkswagen foundation, Germany was acknowledged for financial support.

\section{REFERENCES}

1. www.ethnobiomed.com/content/supplymentary/1746-4269-614-s, October 2011

2. Kumar, J., Mishra G. P., Naik P. K., Murkute, A. A., and Srivastava, R. B. 2011. African Journal of Biotechnology. 10 (37): 7303-7307

3. Zhigzhitzhapova, S. V., Soktoeva, T. E., and Radnaeva, L. D. 2010. Chemistry of Plant Raw Material. 2: 131-133

4. Mathela, C. S., Kharkwal, and Shah, G. C. 1994. Journal of Essential oil Research. 6: 345-348

5. Khanina M. A., Serykh, E. A., Pokrovskii, L. M., and Tkrachev, A. V. 2000. Khim Rastit. Syr ya, 3: 77

6. Suleimenov, E. M., Tkachev A. V., and Adekenov, S. M. 2010. Chemistry of Natural Compounds. 46 (1): 135-139

7. Jingda, C., Youmin, W. 1999. Jiangxi Science. 17(3): 1871898

Mathela, C. S., Kharkwal, H., Shah, G. C. 1994. Journal of Essential Oil Research. 6 (4): 345-348

9. Parajuli, R R., Tiwari R. D., Chaudhary R. P., and Gupta, V. N. 2005. Scientific World. 3: 39-43

10. Vagie E., Simardi B., Suhajda A., Hethadhi E. 2005. Food Research International. 38 (1): 51-57
11. Regmi P.R. 2040. Nepalka Dharmic Botbiruwa. Nepal Rajakiye Prgya Pratisthan

12. Baser, K. H. C., Kirimer, N., Tuemen, G. 1993. Journal of Essential Oil Research. 5 (5): 577-579

13. Vera, R. R., Chang-Ming, J. 1999. Food Chemistry. 66(2): 143145

14. Barazandeh, M. M. 2001. Journal of Essential Oil Research. 13(2): 76-77

15. Ramos, S., Rojas, L. B., Lucena, M. E. 2011 Journal of Essential Oil Research. 23 (5), 45-49

16. Raina, A. P., Negi, K. S. 2012. Chemistry of Natural Compounds. 47(6): 1015

17 Yang, Y. C., Lee, S. H., Marshall, C., Ahn, Y. J. 2009. Journal of Agriculture and Food Chemistry. 57 (6): 2282-2287

18. Joshi B., Lekhak S., Sharma A. 2009 Kathmandu University Journal of Science, Engineering and Technology. 5 (I): 143150

19. Guenther, E. The essential oils. 1960 D-Van Nostrand company, Princetron, New Jersey, New York. 1: 237-306

20. Vokou, D., Kokkini, S., Bessiere, J. M. 1993. Systematic Ecology. 21: 287-295 